\title{
Is the Infection Rate in Primary THA Increased After Steroid Injection?
}

\author{
Geert Meermans MD, Kristoff Corten MD, \\ Jean-Pierre Simon MD, PhD
}

Received: 30 November 2011/Accepted: 1 May 2012/Published online: 19 May 2012

(C) The Association of Bone and Joint Surgeons (B) 2012

\begin{abstract}
Background Injection of the hip is performed for diagnostic and therapeutic reasons. Articular cartilage deterioration and increased risk of prosthetic infection have been reported with steroid injections. However, the literature contains contradictory reports on an increased risk of infection after a subsequent THA.
\end{abstract}

Each author certifies that he or she, or a member of his or her immediate family, has no commercial associations (eg, consultancies, stock ownership, equity interest, patent/licensing arrangements, etc) that might pose a conflict of interest in connection with the submitted article.

All ICMJE Conflict of Interest Forms for authors and Clinical Orthopaedics and Related Research editors and board members are on file with the publication and can be viewed on request.

Clinical Orthopaedics and Related Research neither advocates nor endorses the use of any treatment, drug, or device. Readers are encouraged to always seek additional information, including FDA approval status, of any drug or device before clinical use.

Each author certifies that his or her institution approved the human protocol for this investigation, that all investigations were conducted in conformity with ethical principles of research, and that informed consent for participation in the study was obtained.

This work was performed at University Hospital Pellenberg, Pellenberg, Belgium.

G. Meermans

Marie-Josélaan 19, 2600 Berchem, Belgium

G. Meermans $(\bowtie)$

Department of Orthopaedics, Lievensberg Hospital,

Bergen Op Zoom, The Netherlands

e-mail: geertmeermans@hotmail.com

K. Corten, J.-P. Simon

Department of Orthopaedics, University Hospital

Pellenberg, Pellenberg, Belgium
Questions/Purposes We asked whether intraarticular steroid injection increased the rate of infection of a subsequent THA.

Methods We retrospectively reviewed records of 175 patients in whom intraarticular steroid injections were given under strictly aseptic conditions using a lateral approach within 1 year before THA. These patients were matched with others from our database who had not received an injection for comorbidities, and for American Society of Anesthesiologists score, age, BMI, sex, type of implant, and year of THA.

Results We found no differences in the rate of deep or superficial infection between the two groups. One patient in the injected group and one in the control group had a late chronic infection. In three patients in the injected group and one in the control group, one of the intraoperative cultures was positive. Five patients in the injected group and seven in the control group had superficial infections develop. In seven patients in the injected group and five in the control group, there was prolonged wound drainage ( $>5$ days). None of these patients had a deep wound infection at latest followup. Conclusions When used in strictly aseptic conditions, intraarticular steroid injection of the hip did not increase the risk of infection in patients subsequently undergoing THA.

Level of Evidence Level III, therapeutic study. See Instructions for Authors for a complete description of levels of evidence.

\section{Introduction}

Steroid injections of the hip can be administered for diagnostic $[8,11,20,22]$ and therapeutic reasons [9, 28, $32,43]$, particularly to alleviate inflammatory symptoms 
that can be associated with moderate or end-stage osteoarthritis (OA) of the joint. The radiographic findings of OA are not always conclusive or in relation to the symptoms expressed by the patient. In conjunction with an intraarticular injection of a long-acting anesthetic, steroids can be used for diagnostic purposes to distinguish intrinsic from extrinsic sources of pain such as that originating in the spine $[8,11,20,22]$. The duration and efficacy of pain relief then can be indicative of the source of pain $[9,28,32$, 43]. Although steroid injections in the hip are not recommended in the treatment guidelines provided by the American College of Rheumatology for OA of the hip, they can be helpful in clinical practice when patients with moderate or end-stage OA are not willing or suitable to undergo a THA in the short term [2].

Various adverse effects have been reported with the use of steroids, including articular cartilage deterioration [3], tendon rupture [16, 42], septic arthritis [27, 30], and increased risk of joint infection [4]. The data regarding an association between an increased risk for a periprosthetic joint infection (PJI) of a THA after an intraarticular steroid injection are conflicting. Two reports [21, 24] showed more PJIs in a group of patients who had an intraarticular steroid injection in the hip before they had a THA. In two other studies, there was no increase in PJIs in patients who had THAs after intraarticular injections of a steroid into the ipsilateral hip [7, 40].

We therefore determined whether intraarticular steroid injections under strictly aseptic conditions increased the rates of infection of a subsequent THA.

\section{Patients and Methods}

We retrospectively created matched cohorts from the medical records of 2915 THAs, performed between January 1998 and December 2006, in 2633 patients with OA of the hip who received intraarticular steroid injections less than 12 months before THA and patients who did not receive steroid injections before THA. All patients were operated on by the same surgeon (JS) or under his direct supervision. Cases were identified by inspection of the records of the operating theater. During this period, 1094 steroid injections were used in 831 patients. Of these 831 patients, 309 (37\%) were given an intraarticular steroid injection and subsequently had a THA. In 175 patients (182 THAs, 6\%), the intraarticular steroid injection was given within 1 year of the primary THA (Fig. 1). We excluded patients with any history of acetabular or femoral fracture, joint infection, previous surgery on the index hip, or tumor of the acetabulum or femur. The 182 THAs in 175 patients were matched with a control group of 182 primary THAs in 175 patients who did not receive

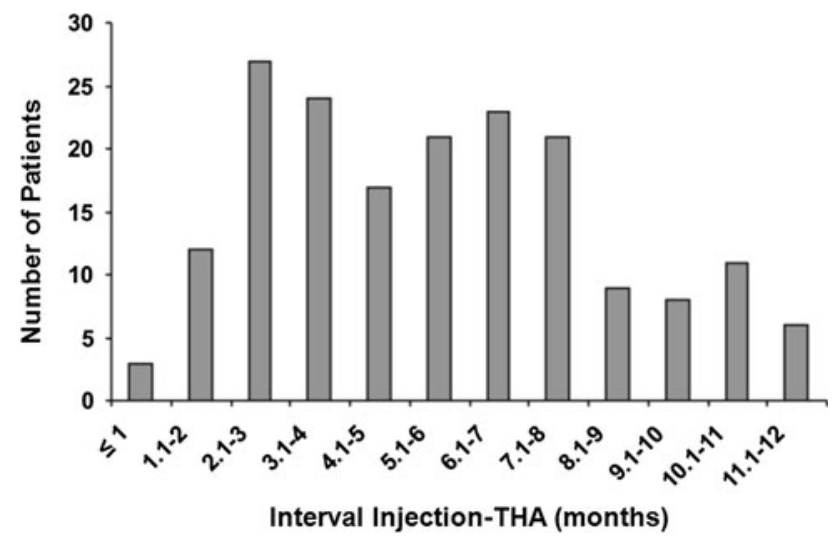

Fig. 1 A bar chart shows the number of patients in relation to the interval between steroid injection and THA.

intraarticular steroid injections. The patients who had not received injections were matched from our database in descending order of priority by comorbidities, American Society of Anesthesiologists (ASA) preoperative score, age, BMI, sex, type of implant, and year of THA. If exclusion criteria were encountered while gathering information from the database for patients who did not receive injections, then the next closest match was used. The baseline parameters of comorbidities, BMI, age, sex, type of implant, and followup were similar in the two groups (Table 1). The mean ASA score was 1.7 for both groups. The mean time between steroid injection and THA was 155 days. At last followup, 16 patients had died, nine in the injected group and seven in the control group (Table 2). All patients died of causes unrelated to the THA and more than 1 year postoperatively (mean, 84 months). Minimum followup for both groups was 12 months (mean, 71 months; range, 12-131 months). Mean followup was 72 months (range, 12-131 months) for the injected group and 71 months (range, 15-129 months) for the control group. The protocol for data collection was approved by our institutional ethics committee.

All intraarticular injections were given by one surgeon (JS) in the operating theater under strict aseptic conditions. The skin was prepared using a chlorhexidine solution and draped. Local anesthetic (levobupivacaine; Abbott Laboratories, Kent, UK) was infiltrated into the skin. A spinal needle routinely was used to infiltrate the hip using a lateral approach. Fluoroscopy was used to confirm correct positioning of the needle. The intraarticular injection was a combination of $80 \mathrm{mg}$ methylprednisolone (Pfizer, Elsene, Belgium) and between 1 and $3 \mathrm{~mL}(5-15 \mathrm{mg})$ levobupivacaine.

All THAs were performed by the same surgeon (JS) or under his direct supervision through a posterior approach using standard techniques. All patients received intravenous antibiotics (cefazoline $2 \mathrm{~g}$; Biopharma, Rome, Italy) at the 
Table 1. Demographics of patients

\begin{tabular}{|c|c|c|c|}
\hline Parameters & $\begin{array}{l}\text { Injected } \\
\text { group }\end{array}$ & $\begin{array}{l}\text { Control } \\
\text { group }\end{array}$ & $\mathrm{p}$ value \\
\hline Patients & 175 & 175 & \\
\hline Age (years)* & $66.4(18-86)$ & $66.6(18-85)$ & 0.83 \\
\hline $\operatorname{Sex}(\mathrm{M} / \mathrm{F})$ & $48 / 127$ & $50 / 125$ & 0.91 \\
\hline Height $(\mathrm{cm})^{*}$ & $\begin{array}{l}168.5 \\
\quad(141-184)\end{array}$ & $\begin{array}{l}167.8 \\
\quad(152-186)\end{array}$ & 0.85 \\
\hline Weight $(\mathrm{kg})^{*}$ & $75.6(45-142)$ & $74.9(51-135)$ & 0.90 \\
\hline BMI $\left(\mathrm{kg} / \mathrm{m}^{2}\right)^{*}$ & $\begin{array}{l}27.8 \\
\quad(17.4-43.8)\end{array}$ & $\begin{array}{l}27.6 \\
\quad(17.3-43.5)\end{array}$ & 0.83 \\
\hline \multicolumn{4}{|l|}{ Diagnosis } \\
\hline Osteoarthritis & 151 & 149 & 0.87 \\
\hline Rheumatoid arthritis & 10 & 10 & 1.00 \\
\hline Dysplasia & 12 & 14 & 0.83 \\
\hline Osteonecrosis & 2 & 2 & 1.00 \\
\hline \multicolumn{4}{|l|}{ Comorbid conditions } \\
\hline Diabetes mellitus & 20 & 18 & 0.86 \\
\hline Myocardial infarction & 16 & 20 & 0.59 \\
\hline Congestive heart failure & 8 & 5 & 0.57 \\
\hline $\begin{array}{l}\text { Peripheral vascular } \\
\text { disease }\end{array}$ & 12 & 13 & 1.00 \\
\hline $\begin{array}{l}\text { Cerebrovascular } \\
\text { accident }\end{array}$ & 6 & 4 & 0.75 \\
\hline $\begin{array}{l}\text { Chronic obstructive } \\
\text { pulmonary disease }\end{array}$ & 12 & 15 & 0.68 \\
\hline Renal disease & 6 & 8 & 0.78 \\
\hline Malignant disease & 10 & 8 & 0.80 \\
\hline Immunosuppression & 13 & 13 & 1.00 \\
\hline ASA score* & $1.72(1-3)$ & $1.73(1-3)$ & 0.79 \\
\hline Followup (months)* & $\begin{array}{l}72.14 \\
\quad(12-131)\end{array}$ & $\begin{array}{l}70.52 \\
\quad(15-129)\end{array}$ & 0.68 \\
\hline
\end{tabular}

* The values are given as the mean with the range in parentheses. $\mathrm{M}=$ male, $\mathrm{F}=$ female, $\mathrm{BMI}=$ body mass index, ASA = American Society of Anesthesiologists.

Table 2. Complications

\begin{tabular}{llllll}
\hline Complication & $\begin{array}{l}\text { Injected } \\
\text { group }\end{array}$ & Percent & $\begin{array}{l}\text { Control } \\
\text { group }\end{array}$ & Percent & p value \\
\hline Death & 9 & 4.95 & 7 & 3.85 & 0.79 \\
Dislocation & 4 & 2.20 & 3 & 2.20 & 1.00 \\
Periprosthetic fracture & 4 & 2.20 & 4 & 2.20 & 1.00 \\
Deep infection & 1 & 0.55 & 1 & 0.55 & 1.00 \\
Superficial infection & 5 & 2.75 & 7 & 3.85 & 0.77 \\
Positive culture & 3 & 1.65 & 1 & 0.55 & 0.62 \\
Prolonged drainage & 7 & 3.85 & 5 & 2.75 & 0.77 \\
\hline
\end{tabular}

time of induction, with two more doses postoperatively within 24 hours. A swab of intraarticular tissue routinely was obtained, and in case of intraarticular fluid, this fluid also was cultured. All patients received a hybrid THA with a cementless cup (Morscher cup [used from January 1997 until November 2000] [n = 52] or Trilogy ${ }^{\circledR}$ cup [used from December 2000 until December 2007] [n = 130]; both from Zimmer, Inc, Warsaw, IN, USA). On the femoral side, the stem (Exeter ${ }^{\mathrm{TM}}$; Stryker-Howmedica, Newbury, UK) was cemented with antibiotic-containing bone cement (Simplex $\mathrm{P}^{\circledR}$; Stryker-Howmedica) using a third-generation cementing technique with a distal bone block, a pressurized lavage system for femoral canal preparation, retrograde injection of the cement with a cement gun with a long nozzle, and pressurization of the cement with a proximal rubber seal. Surgical helmets were worn in all cases and all the procedures were performed under vertical laminar airflow. Deep closed suction drains were inserted in all hips during this period and routinely removed 48 hours after surgery. Bladder catheters were used only in patients with known urinary retention problems or difficult urination. All patients received general anesthesia.

All patients were followed at 6 weeks, 1 year, 2 years, and biannually thereafter. In case of unexplained pain and/ or delayed wound healing, postoperative superficial infection, or persisting wound drainage, we obtained laboratory tests, radiographs, and a bone scan. When there was suspicion in the history for infection and C-reactive protein (CRP) or erythrocyte sedimentation rate (ESR) were increased or if there was a positive bone scan, a joint aspiration and biopsy were performed [25].

The main outcome measure was PJI. Secondary outcome measures were superficial infection, prolonged wound drainage ( $>5$ days), positive intraoperative culture, overall complications, and implant survival. PJI was defined as (1) a sinus tract communicating with the implant, (2) the identical pathogen isolated from two or more separate tissue samples, or (3) the presence of purulence in the joint. Growth from one specimen only usually was regarded as a contaminant, but only after discussion with a consultant microbiologist who specialized in bone and joint infection and after reviewing all available data from that patient [29]. A superficial infection was defined as any wound infection that involved only the skin and subcutaneous tissue that was confirmed with ultrasound or during surgical debridement, an organism isolated from an aseptically obtained culture, or signs of infection including a painful wound, swelling, redness, or heat [15].

To ensure consistency, one of us (GM) extracted and analyzed all data. Data extraction included a review of all available hospital records of blood chemistry, microbiology (including a routine intraoperative sample), bone scans, consultations, operative and clinic notes, and radiographs. A record was made of wound drainage and cultures, revision surgery, and any investigations for infection, including bone scans, hip aspirations, and CRP level and ESR. The hospital records were available for all 350 patients (175 from the injected group and 175 from the control group). 
A power analysis using the conventional $80 \%$ power, based on a general PJI rate of $1 \%$ and using the $10 \%$ PJI rate in patients receiving a steroid injection before THA reported by Kaspar and de V de Beer [21], showed 122 patients per group would be required to obtain a result that is significant at a $\mathrm{p}$ value less than 0.05 .

We performed statistical analyses using Fisher's exact test for binary variables (sex, diagnosis, comorbid conditions, and complications), Kolmogorov-Smirnov test to test for Gaussian distribution, Student's t-test for continuous variables (age, height, weight, BMI, followup), and MannWhitney test for nonparametric variables (ASA score). The cumulative risks of deep infection and revision for any reason were estimated separately for hips replaced after an intraarticular steroid injection and for hips replaced without injection by using the Kaplan-Meier survival method [19]. A $\log$ rank test was used to determine the difference. We performed all analyses using SPSS $^{\circledR} 15.0$ (SPSS Inc, Chicago, IL, USA).

\section{Results}

We found no differences between the injected and control groups for the rate of PJI (Table 2). One patient in the injected group had a deep infection of the hip 10 months postoperatively. This patient had a steroid injection 5 weeks before THA and was readmitted 4 weeks postoperatively because of wound drainage that was treated by his general practitioner with oral antibiotics. The wound was irrigated and débrided and a femoral head and liner exchange were performed followed by 6 weeks of intravenous antibiotics. Intraoperative cultures were negative. Because of persistent hip pain and slightly elevated inflammatory parameters $(\mathrm{CRP}, 6.5 \mathrm{mg} / \mathrm{L}$ [normal value, $\leq 5 \mathrm{mg} / \mathrm{L}$ ]; ESR, $40 \mathrm{~mm} /$ hour [normal value, $\leq 30 \mathrm{~mm} /$ hour]), further investigations were deemed necessary. Repeat cultures and a bone scan were negative. Twelve months postoperatively, the patient was treated with a twostage revision. Reimplantation was performed 3 months after removal of the prosthesis from the primary THA. Further examinations showed normal CRP and ESR levels and negative bone scans and aspiration cultures. One patient in the control group had a late chronic infection. The patient presented 12 months postoperatively with a painful THA after being pain free initially. Examinations showed elevated inflammatory parameters and a positive bone scan. Aspiration showed Staphylococcus aureus. The patient underwent a two-stage revision procedure. Followup was uneventful. The overall revision rate for infection in the same period was eight of 2915 hips $(0.27 \%)$. In both groups four patients were examined with a full blood count, CRP and ESR measurements, and a bone scan owing to persistent pain in the hip region. Two patients in the injected group and one in the control group underwent aspiration and biopsy because of slightly elevated CRP and ESR, but no organism grew on culture specimens. At final followup, symptoms in all these patients had resolved.

We found no differences between the injected and control groups for rate of superficial infections (Table 2). Ten patients were treated with dressing changes and intravenous antibiotics and the other two (both in the injected group) underwent reoperations with débridement of the wound and irrigation with documentation of integrity of the deep fascia. There was no growth from cultures obtained at the time of débridement. In 12 patients, there was prolonged wound drainage, which in all cases was treated with dressing changes and which resolved spontaneously. None of these patients had a deep wound infection at latest followup. In four patients, one of the intraoperative cultures was positive. They were considered patients with a normal profile and did not receive any treatment. None of them had a deep wound infection at latest followup. There were no differences between the injected and control groups regarding complications (Table 2). There also were no differences between groups for survival rates with revision for any reason or revision for infection as the end point (Fig. 2).
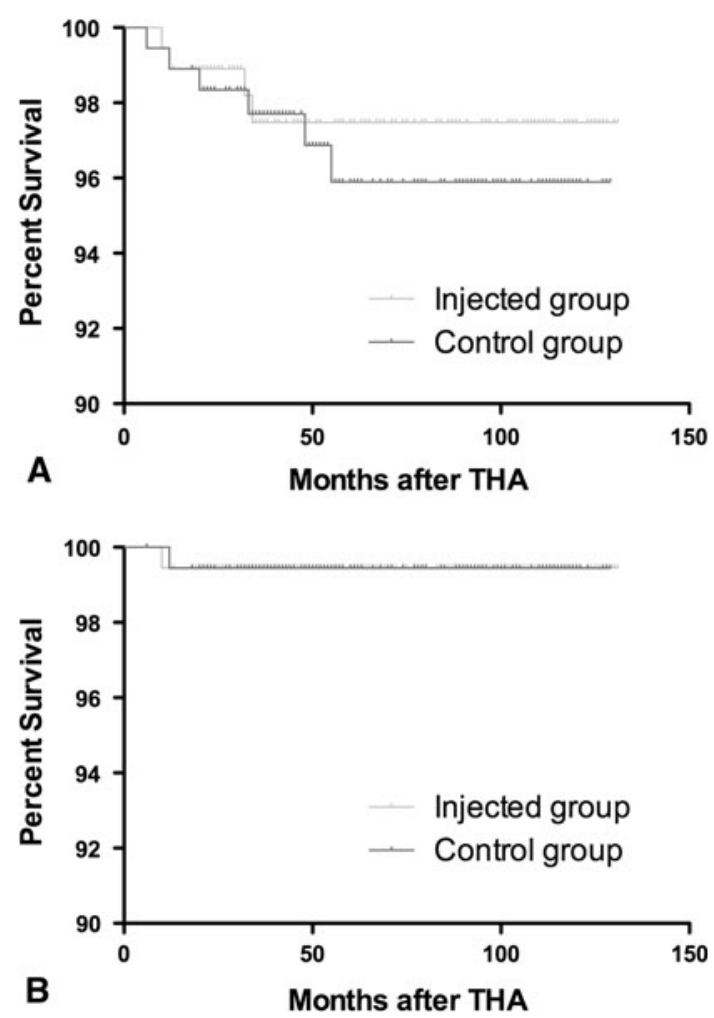

Fig. 2A-B Survivorship curves as determined by the Kaplan-Meier method are shown with $(\mathbf{A})$ revision for any reason as the end point and (B) infection as the end point. Tick marks indicate censored data. 


\section{Discussion}

Periprosthetic infection is a major complication of a THA. It occurs in only a small number of patients but results in substantial morbidity and a decline in functional outcome. Several prophylactic measures have been used to successfully reduce the infection rate to less than $1 \%$ [5, 6, 36-38]. There has been concern regarding an increased risk of postoperative infection after intraarticular steroid injection $[21,24]$. We therefore investigated whether intraarticular steroid injections within 1 year of subsequent primary THA would increase the rate of PJIs compared with a matched group not receiving steroid injections.

There are several limitations to our study. First, medical comorbidities affect surgical site infection rates. We matched the comorbidities of the patient cohorts, including rheumatoid arthritis and malignancy, but in some of these conditions, there is a wide range of severity and inherent immunosuppressive potential, which we did not account for $[6,12,33,45]$. In addition, patients with these conditions generally are taking several medications that may have a dose-dependent immunosuppressive profile [14]. Nutritional status [13, 14, 17, 39] and obesity [41] are predisposing factors to deep joint infection. The nutritional status was not routinely checked for every patient in our study as this was left to the discretion of the operating surgeon. BMI was included in the matching process. Second, another risk factor for surgical site infection is admission to the hospital from a healthcare facility, which was not controlled in our study [23]. Third, we did not record or control for surgical times. One study suggested longer surgical time may be associated with an increased infection risk [46]. More recent studies however, reported no correlation between operative time and postoperative infection [10, 34]. In our study, all patients were operated on by the same surgeon or under his direct supervision and therefore the operating times in the two patient cohorts are expected to be similar. A similar discrepancy exists regarding the use of drains. Although there is no agreement in the literature regarding the use of drains after hip surgery, their use was not found to be associated with an increased incidence of periprosthetic infection [10, 44]. In our study, drains were used routinely in all patients in both groups and removed within 48 hours postoperatively. Fourth, there are discrepancies reported regarding some components of the diagnostic criteria for superficial surgical site infection [1]. We applied the guidelines of the $\mathrm{CDC}$, which have been used for reporting infection rates $[23,26,34]$. Fifth, according to one study [24], 1.34\% of the patients (three of 224) had a deep infection develop after steroid injection compared with $0.45 \%$ of patients (one of 224) in the noninjected group. A power study using these numbers and the conventional $80 \%$ power would require 1641 patients per group to be included. To achieve this, a large multicenter trial would be necessary. Sixth, in recent guidelines of the Musculoskeletal Infection Society histologic examination of the periprosthetic tissues, synovial leukocyte count and neutrophil percentage are used as criteria in the definition of PJI [29]. These criteria were not used at the time of our study, but both tests currently are used in our department for the workup of patients suspected of having a PJI. Outcome of these additional tests would not have influenced the outcome of patients in the current study. Seventh, the mean followup after THA was 71.33 months (range, 12-131 months). One study showed that in a large series even though the majority of infections $(81 \%)$ were diagnosed during the first 2 years, additional infections may become evident with time [31]. Eighth, there were patients with positive cultures in the injected group (three in the injected group versus one in the control group). This did not influence the outcome of the patients and none subsequently had a surgical site infection, as was reported previously [35].

We found no differences between the injected and control groups for the rate of PJI (both $0.55 \%$ ) or superficial infection $(2.75 \%$ versus $3.85 \%)$. In a study by Kaspar and de V de Beer [21], a group of 40 patients who had intraarticular steroid injections and subsequent THAs were compared with 40 control patients who had THAs without receiving steroid injections. There were five revisions in the injection group (four for PJI) compared with no revisions in the control group. This resulted in an overall revision rate of $12.5 \%$ in this group compared with a $1.02 \%$ revision rate (10 of 979 THAs) of concomitant primary THAs performed at their hospital during the same period. McIntosh et al. [24] retrospectively reviewed 224 primary THAs done within a year of intraarticular steroid injection. In three patients who had a PJI after steroid injections (compared with one patient in the noninjected group) the mean time from injection to THA was 44 days. The patient from the injected group in the aforementioned study who had a PJI had a steroid injection 35 days before the THA (Table 3 ).

Steroids can provide symptomatic control in the short term and may allow surgery to be delayed until a more appropriate time. The problem is that it is not possible to predict which patients will respond positively to an injection [18]. Two studies [21, 24] reported a greater rate of infection in THAs performed after a previous steroid injection. As yet, it is unclear which component of the injection procedure may be culpable: the arthrography dye, the steroid or its depot vehicle, contamination of the local anesthetic, the invasiveness of a needle through prepared skin, any breech of sterile technique, or the time between the steroid injection and the THA.

Our findings suggest an intraarticular steroid injection through a lateral approach to the hip is safe when the 
Table 3. Infections in primary THAs after steroid injections reported in the literature

\begin{tabular}{|c|c|c|c|c|c|}
\hline \multirow[t]{2}{*}{ Study } & \multirow[t]{2}{*}{ Study design } & \multirow{2}{*}{$\begin{array}{l}\text { Number } \\
\text { of patients }\end{array}$} & \multirow{2}{*}{$\begin{array}{l}\text { Infection rate } \\
\text { injection group }\end{array}$} & \multicolumn{2}{|l|}{ Injection } \\
\hline & & & & Location & Provider \\
\hline $\begin{array}{l}\text { Kaspar and de } \\
\text { V de Beer [21] }\end{array}$ & $\begin{array}{l}\text { Retrospective } \\
\text { matched cohort }\end{array}$ & $\begin{array}{l}40 \\
\text { (40 hips) }\end{array}$ & $\begin{array}{l}10 \% \\
\text { (4 patients) }\end{array}$ & Fluoroscopy suite & Radiologist \\
\hline $\begin{array}{l}\text { McIntosh et al. } \\
\text { [24] }\end{array}$ & $\begin{array}{l}\text { Retrospective } \\
\text { matched cohort }\end{array}$ & $\begin{array}{l}217 \\
\text { (224 hips) }\end{array}$ & $\begin{array}{l}1.34 \% \\
\text { (3 patients) }\end{array}$ & Fluoroscopy suite & Radiologist \\
\hline Chitre et al. [7] & Retrospective cohort & $\begin{array}{l}36 \\
\text { (36 hips) }\end{array}$ & $\begin{array}{l}0 \% \\
\text { (0 patients) }\end{array}$ & Operating theatre & Surgeon \\
\hline $\begin{array}{l}\text { Sreekumar et al. } \\
\quad[40]\end{array}$ & $\begin{array}{l}\text { Retrospective } \\
\text { matched cohort }\end{array}$ & $\begin{array}{l}66 \\
\text { (68 hips) }\end{array}$ & $\begin{array}{l}0 \% \\
\text { (0 patients) }\end{array}$ & Fluoroscopy suite & Not specified \\
\hline Current study & $\begin{array}{l}\text { Retrospective } \\
\text { matched cohort }\end{array}$ & $\begin{array}{l}175 \\
\text { (182 hips) }\end{array}$ & $\begin{array}{l}0.55 \% \\
\text { (1 patient) }\end{array}$ & Operating theatre & Surgeon \\
\hline
\end{tabular}

injection is given in the operating theater and a strictly aseptic technique is used. Based on previous findings [24], caution should be used when planning a THA within 2 months after an intraarticular steroid injection.

\section{References}

1. Allami MK, Jamil W, Fourie B, Ashton V, Gregg PJ. Superficial incisional infection in arthroplasty of the lower limb: interobserver reliability of the current diagnostic criteria. $J$ Bone Joint Surg Br. 2005;87:1267-1271.

2. American College of Rheumatology Subcommittee on Osteoarthritis Guidelines. Recommendations for the medical management of osteoarthritis of the hip and knee: 2000 update. Arthritis Rheum. 2000;43:1905-1915.

3. Behrens F, Shepard N, Mitchell N. Alterations of rabbit articular cartilage by intra-articular injections of glucocorticoids. $J$ Bone Joint Surg Am. 1975;57:70-76.

4. Berbari EF, Hanssen AD, Duffy MC, Steckelberg JM, Ilstrup DM, Harmsen WS, Osmon DR. Risk factors for prosthetic joint infection: case-control study. Clin Infect Dis. 1998;27:1247-1254.

5. Charnley J. Postoperative infection after total hip replacement with special reference to air contamination in the operating room. Clin Orthop Relat Res. 1972;87:167-187.

6. Charnley J, Eftekhar N. Postoperative infection in total prosthetic replacement arthroplasty of the hip-joint: with special reference to the bacterial content of the air of the operating room. $\mathrm{Br}$ J Surg. 1969;56:641-649.

7. Chitre AR, Fehily MJ, Bamford DJ. Total hip replacement after intra-articular injection of local anaesthetic and steroid. $J$ Bone Joint Surg Br. 2007;89:166-168.

8. Crawford RW, Gie GA, Ling RS, Murray DW. Diagnostic value of intra-articular anaesthetic in primary osteoarthritis of the hip. J Bone Joint Surg Br. 1998;80:279-281.

9. Creamer P. Intra-articular corticosteroid treatment in osteoarthritis. Curr Opin Rheumatol. 1999;11:417-421.

10. Dowsey MM, Choong PF. Obesity is a major risk factor for prosthetic infection after primary hip arthroplasty. Clin Orthop Relat Res. 2008;466:153-158.

11. Faraj AA, Kumaraguru P, Kosygan K. Intra-articular bupivacaine hip injection in differentiation of coxarthrosis from referred thigh pain: a 10 year study. Acta Orthop Belg. 2003;69:518-521.
12. Fitzgerald RH Jr, Nolan DR, Ilstrup DM, Van Scoy RE, Washington JA 2nd, Coventry MB. Deep wound sepsis following total hip arthroplasty. J Bone Joint Surg Am. 1977;59:847-855.

13. Gherini S, Vaughn BK, Lombardi AV Jr, Mallory TH. Delayed wound healing and nutritional deficiencies after total hip arthroplasty. Clin Orthop Relat Res. 1993;293:188-195.

14. Greene KA, Wilde AH, Stulberg BN. Preoperative nutritional status of total joint patients: relationship to postoperative wound complications. J Arthroplasty. 1991;6:321-325.

15. Horan TC, Gaynes RP, Martone WJ, Jarvis WR, Emori TG. CDC definitions of nosocomial surgical site infections, 1992: a modification of CDC definitions of surgical wound infections. Infect Control Hosp Epidemiol. 1992;13:606-608.

16. Ismail AM, Balakrishnan R, Rajakumar MK, Lumpur K. Rupture of patellar ligament after steroid infiltration: report of a case. J Bone Joint Surg Br. 1969;51:503-505.

17. Jensen JE, Jensen TG, Smith TK, Johnston DA, Dudrick SJ. Nutrition in orthopaedic surgery. J Bone Joint Surg Am. 1982;64: $1263-1272$.

18. Jones A, Doherty M. Intra-articular corticosteroids are effective in osteoarthritis but there are no clinical predictors of response. Ann Rheum Dis. 1996;55:829-832.

19. Kaplan EL, Meier P. Nonparametric estimation from incomplete observations. J Am Stat Assoc 1958;53:457-481.

20. Kaspar J, Kaspar S, Orme C, de Beer J de V. Intra-articular steroid hip injection for osteoarthritis: a survey of orthopedic surgeons in Ontario. Can J Surg. 2005;48:461-469.

21. Kaspar $\mathrm{S}$, de $\mathrm{V}$ de Beer J. Infection in hip arthroplasty after previous injection of steroid. J Bone Joint Surg Br. 2005;87: 454-457.

22. Kleiner JB, Thorne RP, Curd JG. The value of bupivicaine hip injection in the differentiation of coxarthrosis from lower extremity neuropathy. J Rheumatol. 1991;18:422-427.

23. Lee J, Singletary R, Schmader K, Anderson DJ, Bolognesi M, Kaye KS. Surgical site infection in the elderly following orthopaedic surgery: risk factors and outcomes. J Bone Joint Surg Am. 2006;88:1705-1712.

24. McIntosh AL, Hanssen AD, Wenger DE, Osmon DR. Recent intraarticular steroid injection may increase infection rates in primary THA. Clin Orthop Relat Res. 2006;451:50-54.

25. Meermans G, Haddad FS. Is there a role for tissue biopsy in the diagnosis of periprosthetic infection? Clin Orthop Relat Res. 2010;468:1410-1417.

26. Morgan M, Black J, Bone F, Fry C, Harris S, Hogg S, Holmes A, Hughes S, Looker N, McIlvenny G, Nixon J, Nolan J, Noone A, 
Reilly J, Richards J, Smyth E, Howard A. Clinician-led surgical site infection surveillance of orthopaedic procedures: a UK multicentre pilot study. J Hosp Infect. 2005;60:201-212.

27. Nallamshetty L, Buchowski JM, Nazarian LA, Narula S, Musto M, Ahn NU, Frassica FJ. Septic arthritis of the hip following cortisone injection: case report and review of the literature. Clin Imaging. 2003;27:225-228.

28. Neustadt DH. Local steroid injections: comment on the American College of Rheumatology guidelines for the management of osteoarthritis of the hip and on the letter by Swezey. Arthritis Rheum. 1997;40:1914-1915.

29. Parvizi J, Zmistowski B, Berbari EF, Bauer TW, Springer BD, Della Valle CJ, Garvin KL, Mont MA, Wongworawat MD, Zalavras CG. New definition for periprosthetic joint infection: from the Workgroup of the Musculoskeletal Infection Society. Clin Orthop Relat Res. 2011;469:2992-2994.

30. Perry CR. Septic arthritis. Am J Orthop (Belle Mead NJ). 1999; 28:168-178.

31. Phillips JE, Crane TP, Noy M, Elliott TS, Grimer RJ. The incidence of deep prosthetic infections in a specialist orthopaedic hospital: a 15-year prospective survey. J Bone Joint Surg Br. 2006;88:943-948.

32. Plant MJ, Borg AA, Dziedzic K, Saklatvala J, Dawes PT. Radiographic patterns and response to corticosteroid hip injection. Ann Rheum Dis. 1997;56:476-480.

33. Poss R, Thornhill TS, Ewald FC, Thomas WH, Batte NJ, Sledge CB. Factors influencing the incidence and outcome of infection following total joint arthroplasty. Clin Orthop Relat Res. 1984;182:117-126.

34. Ridgeway S, Wilson J, Charlet A, Kafatos G, Pearson A, Coello $\mathrm{R}$. Infection of the surgical site after arthroplasty of the hip. J Bone Joint Surg Br. 2005;87:844-850.

35. Ritter MA, Stringer EA. Intraoperative wound cultures: their value and long-term effect on the patient. Clin Orthop Relat Res. 1981;155:180-185.
36. Salvati EA, Robinson RP, Zeno SM, Koslin BL, Brause BD, Wilson PD Jr. Infection rates after 3175 total hip and total knee replacements performed with and without a horizontal unidirectional filtered air-flow system. J Bone Joint Surg Am. 1982;64: 525-535.

37. Salvati EA, Wilson PD Jr, Jolley MN, Vakili F, Aglietti P, Brown GC. A ten-year follow-up study of our first one hundred consecutive Charnley total hip replacements. J Bone Joint Surg Am. 1981;63:753-767.

38. Schutzer SF, Harris WH. Deep-wound infection after total hip replacement under contemporary aseptic conditions. J Bone Joint Surg Am. 1988;70:724-727.

39. Smith TK. Nutrition: its relationship to orthopedic infections. Orthop Clin North Am. 1991;22:373-377.

40. Sreekumar R, Venkiteswaran R, Raut V. Infection in primary hip arthroplasty after previous steroid infiltration. Int Orthop. 2007; $31: 125-128$.

41. Stern SH, Insall JN. Total knee arthroplasty in obese patients. J Bone Joint Surg Am. 1990;72:1400-1404.

42. Sweetnam R. Corticosteroid arthropathy and tendon rupture. J Bone Joint Surg Br. 1969;51:397-398.

43. Swezey RL. Comment on the American College of Rheumatology guidelines for osteoarthritis of the knee and hip. Arthritis Rheum. 1996;39:2083.

44. Walmsley PJ, Kelly MB, Hill RM, Brenkel I. A prospective, randomised, controlled trial of the use of drains in total hip arthroplasty. J Bone Joint Surg Br. 2005;87:1397-1401.

45. Wilson MG, Kelley K, Thornhill TS. Infection as a complication of total knee-replacement arthroplasty: risk factors and treatment in sixty-seven cases. J Bone Joint Surg Am. 1990;72:878883.

46. Yong KS, Kareem BA, Ruslan GN, Harwant S. Risk factors for infection in total hip replacement surgery at Hospital Kuala Lumpur. Med J Malaysia. 2001;56(suppl C):57-60. 